\title{
Are Men from Mars and Women from Venus?
} Bridging the gender learning gap in medical education

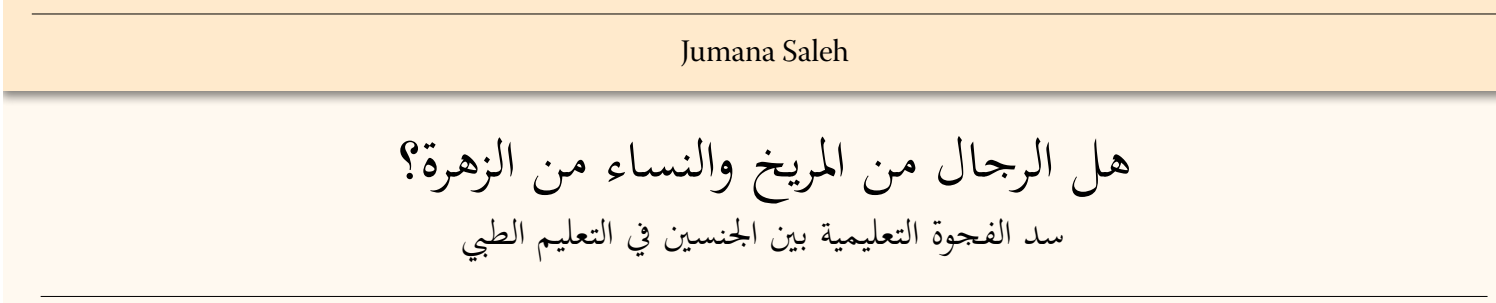

جمانة صالح

$\mathrm{T}$ Here have been tremendous DeVelopments in the area of medical education of late, including the introduction of problembased learning (PBL) and team-based learning (TBL). Undoubtedly, these new methods of teaching have significant benefits in enhancing learning skills and medical learning outcomes. However, it is still too early to conclude that these relatively recent techniques can solve problems that have persisted from following structured curricula in the past. One issue worth highlighting is the gender learning gap. For years, female students have repeatedly shown superior academic results in comparison to their male counterparts. ${ }^{1-3}$ A greater number of women gain admission into medical schools, where they outperform their male colleagues academically; they also go on to earn more graduate degrees. ${ }^{4,5}$ The widening of this gender learning gap-particularly in the medical and healthcare fields-is of growing concern. Reasons for this phenomenon may include social, cultural, psychological and emotional components. ${ }^{4}$

Since the 1960s, various women's equality movements have encouraged the development of environments which support education and career advancements for women. Some researchers claim that the superior academic performance demonstrated by women in medical careers is due to their instinctive desire to help humankind., ${ }^{4,6}$ Women have also been described as being more perceptive to emotions, enabling them to be more caring and empathetic. ${ }^{6}$ Their enhanced academic performance may also be due to goal setting, commitment and discipline in following a structured curriculum, spending more time studying and developing stronger social networks; these attributes may develop as a result of social and cultural customs that encourage women to perform well academically. ${ }^{7}$ One theoretical explanation proposed by Raymond et al. is the influence of family practices, such as parents encouraging gender-specific roles among their children; for example, girls are usually expected to be well-mannered, compliant and accept rules. ${ }^{8}$ These behaviours evidently promote academic achievement in traditional academic settings. ${ }^{9,10}$

Conversely, male students favour less constrained learning environments and focus on achieving high grades in their final tests, developing learning skills to meet this purpose. ${ }^{11-15}$ Nevertheless, researchers have expressed concern that the perceived idea of female students as "highly motivated" may encourage teachers to give them more attention and overlook equally motivated male students, further enhancing the gender learning gap. ${ }^{9}$ Another theory is that increasing numbers of independent, educated and employed mothers are acting as role models for their daughters. ${ }^{9}$ Furthermore, it may be that although women sense their lower status in society compared to men, they anticipate that implementing greater efforts in their education may justly reward them with a more equitable future. In 1989, Mickelson proposed the 'Pollyanna principle' to explain the tendency for individuals to remember agreeable occurrences over unpleasant ones. ${ }^{16}$ In light of this theory, many young women may remain optimistic about their future as, in their view, gender discrimination in the workplace is a problem of the past and society is moving towards gender equity. This may explain the higher academic achievements of young women who have not yet suffered occasions of gender inequality.

Stereotyping in medical education is a significant factor that influences women's academic aspirations by discouraging interest in occupations usually dominated by males, such as engineering and mathematics. ${ }^{17,18}$ The authors of some studies have argued that the gender gap in medical specialties may be due to reinforcement of the idea that genetic 
factors render males more capable of performing in fields related to mathematics and physics. ${ }^{19-21}$ Unfortunately, stereotyping is still apparent in certain medical specialties; in general, more women practice in so-called "feminine" specialisations, such as paediatrics and gynaecology, while more men specialise in "masculine" areas, such as orthopaedic surgery. Moreover, male healthcare practitioners tend to hold positions with higher status and better pay in comparison to their equally qualified female colleagues..$^{22,23}$

The differences in academic performance attributed to effort and engagement, as a result of social and cultural aspects, have been studied extensively. However, there is mounting evidence which indicates that gender disparity in academic performance is inherently associated with biological differences that influence learning behaviours in males and females. The author of The Female Brain highlights that males and females have brains that are biochemically and neurologically programmed to perform different tasks from an early age. ${ }^{15}$ Other researchers have commented that young boys occupy more space when learning, due to their continuous movements, compared to girls., ${ }^{1,15}$ In addition, boys seem to prefer engaging and interacting in rough play, sports and building activities as well as reading action books. ${ }^{1}$ Interestingly, a recent comprehensive study also showed that the neural connections in male and female brains are different; female brains were found to have more connections between the two hemispheres of the brain while males had more connections within each hemisphere. ${ }^{24}$ These findings agree with those of Clements et al., who observed that males prefer to execute individual tasks and are better at performing motor activities than women. ${ }^{25}$

Testosterone, the male hormone, enhances the spatial and visual acuity of the sense organs, affecting activities that require spatial skills such as geometry, physics, engineering and navigation. ${ }^{26-28}$ This may explain why more men become pilots and architects. Specific areas of the male brain mature earlier than females and males have more grey matter related to intelligence, including tasks involving mathematics and problem-solving. ${ }^{29,30}$ On the other hand, increased interhemispheric neural connectivity and the largely increased white matter related to intelligence in female brains renders women more capable of coordinating analytical reasoning and intuition. ${ }^{24}$ As such, women tend to excel in multitasking which requires the use of both hemispheres; this might explain why women are traditionally tasked with handling various household activities and responding to family needs simultaneously. Also, the cerebral cortex in women is highly organised in a pattern which has been linked to increased empathy and creative expression. ${ }^{31,32}$ Nevertheless, it is important to keep in mind that there are more similarities than differences between male and female brains..$^{24}$

In collaboration with other scientists, Dr. Denckla from the Kennedy Krieger Institute found that anatomical differences in the brain-specifically, the language functioning areas of the brain-occur from an early age. ${ }^{33}$ Female fetuses at 26 gestational weeks had a thicker corpus callosum, the nerve tissue connecting the right and left hemispheres of the brain, compared to males; upon listening to certain triggers, the brains of the female fetuses showed activity in both the left and right hemispheres, whereas only the left hemisphere was activated in males. ${ }^{33}$ Dr. Denckla also revealed that the areas of the female brain linked to language skills mature approximately six years earlier than for males, which may result in stronger language and communication skills among women. ${ }^{29,33}$ Clements et al. also provided clear evidence of lateral differences between females and males when processing language versus visuospatial information. ${ }^{25}$ Differences in brain function may also be explained from the perspective of human development. In a hunter-gatherer society, male hunters had to exhibit intense sensory reflexes to be able to detect their prey and kill it without feeling sympathetic. ${ }^{34}$ Strong motor function skills would also have helped men to design hunting tools and weapons. Conversely, greater emotional intelligence may have been a factor that drove women to respond intuitively to the needs of a crying baby without requiring verbal expression. ${ }^{34}$

The adoption of PBL and TBL techniques in medical education, while still advantageous for female students with their proficient communication skills, could be a major shift for male students who can now display their problem-solving skills in suitable academic settings that encourage and nurture their abilities and remove gender-based stereotypes. Gradually, PBL and TBL may remove the academic bias in favour of females, or males in certain specialties, as a result of social, cultural, behavioural and biological factors. Consequently, curricular changes towards PBL and/or TBL approaches may help bridge the gender learning gap in medicine.

\section{References}

1. DiPrete TA, Buchmann C. The Rise of Women: The growing gender gap in education and what it means for American schools, 1st ed. New York, USA: Russell Sage Foundation, 2013. Pp. 1-24.

2. Voyer D, Voyer SD. Gender differences in scholastic achievement: A meta-analysis. Psychol Bull 2014; 140:1174-204. doi: $10.1037 / \mathrm{a} 0036620$ 
3. Stoet G, Geary DC. Sex differences in academic achievement are not related to political, economic, or social equality. Intell 2015; 48:137-51. doi: 10.1016/j.intell.2014.11.006.

4. Ecklund EH, Lincoln AE, Tansey C. Gender segregation in elite academic science. Gend Soc 2012; 26:693-717. doi: 10.1177 /0891243212451904.

5. Penington C. Gender proves large factor in academic performance. From: www.elon.edu/e-web/pendulum/issues/ 2004/3_11/news/gender.xhtml Accessed: Jul 2016.

6. Hojat M, Gonnella JS, Mangione S, Nasca TJ, Veloski JJ, Erdmann JB, et al. Empathy in medical students as related to academic performance, clinical competence and gender. Med Educ 2002; 36:522-7. doi: 10.1046/j.1365-2923.2002.01234.x.

7. Banks JA. Encyclopedia of Diversity in Education, 1st ed Washington, USA: Sage Publications, 2012. doi: 10.4135/ 9781452218533

8. Raymond CL, Benbow CP. Gender differences in mathematics: A function of parental support and student sex typing? Develop Psychol 1986; 22:808-19. doi: 10.1037/0012-1649.22.6.808.

9. Zusman M, Knox D, Lieberman M. Gender differences in reactions to college course requirements or "why females are better students". Coll Stud J 2005; 39:621-6.

10. Stockard J, Schmuck K, Kempner P, Williams S, Edson K, Smith MA. Sex Equity in Education. New York, USA: Academic Press, 1980

11. Zhou YX, Zhao ZT, Li L, Wan CS, Peng CH, Yang J, et al. Predictors of first-year GPA of medical students: A longitudinal study of 1285 matriculates in China. BMC Med Educ 2014; 14:87. doi: 10.1186/1472-6920-14-87.

12. Gnaulati E. Why girls tend to get better grades than boys do. From: www.theatlantic.com/education/archive/2014/09/ why-girls-get-better-grades-than-boys-do/380318/ Accessed: Jul 2016

13. American Psychological Association. Girls make higher grades than boys in all school subjects, analysis finds. From: www.apa. org/news/press/releases/2014/04/girls-grades.aspx Accessed: Jul 2016.

14. Duckworth AL, Seligman MEP. Self-discipline gives girls the edge: Gender in self-discipline, grades, and achievement test scores. J Educ Psychol 2006; 98:198-208. doi: 10.1037/00220663.98.1.198.

15. Brizendine L. The Female Brain, 1st ed. New York, USA Broadway Books, 2006. Pp. 1-10.

16. Mickelson RA. Why does Jane read and write so well? The anomaly of women's achievement. Sociol Educ 1989; 62:47-63. doi: $10.2307 / 2112823$.

17. Correll SJ. Constraints into preferences: Gender, status, and emerging career aspirations. Am Sociol Rev 2004; 69:93-113. doi: 10.1177/000312240406900106.

18. Rydell RJ, Rydell MT, Boucher KL. The effect of negative performance stereotypes on learning. J Pers Soc Psychol 2010; 99:883-96. doi: 10.1037/a0021139.
19. Steele JR, Ambady N. "Math is hard!" The effect of gender priming on women's attitudes. J Exp Soc Psychol 2006; 42:428-36. doi: 10.1016/j.jesp.2005.06.003.

20. Thoman DB, White PH, Yamawaki N, Koishi H. Variations of gender-math stereotype content affect women's vulnerability to stereotype threat. Sex Roles 2008; 58:702-12. doi: 10.1007/ s11199-008-9390-x.

21. Dweck CS. Is math a gift? Beliefs that put females at risk. From: http://psychology.stanford.edu/sites/all/files/cdweckmath gift_0.pdf Accessed: Jul 2016.

22. Jagsi R, Griffith KA, DeCastro RA, Ubel P. Sex, role models, and specialty choices among graduates of US medical schools in 2006-2008. J Am Coll Surg 2014; 218:345-52. doi: 10.1016/j. jamcollsurg.2013.11.012

23. Fox M. White male doctors earn more than women and black peers, study finds. From: www.nbcnews.com/health/healthnews/white-male-doctors-earn-more-women-black-peersstudy-finds-n588146 Accessed: Jul 2016

24. Ingalhalikar $M$, Smith $A$, Parker $D$, Satterthwaite TD, Elliott MA, Ruparel K, et al. Sex differences in the structural connectome of the human brain. Proc Natl Acad Sci U S A 2014; 111:823-8. doi: 10.1073/pnas.1316909110.

25. Clements AM, Rimrodt SL, Abel JR, Blankner JG, Mostofsky SH, Pekar JJ, et al. Sex differences in cerebral laterality of language and visuospatial processing. Brain Lang 2006; 98:150-8. doi: 10.1016/j.bandl.2006.04.007.

26. Abramov I, Gordon J, Feldman O, Chavarga A. Sex \& vision I: Spatio-temporal resolution. Biol Sex Differ 2012; 3:20. doi: 10.1186/2042-6410-3-20.

27. Halpern DF. Sex differences in intelligence: Implications for education. Am Psychol 1997; 52:1091-102. doi: 10.1037/0003066X.52.10.1091.

28. Celec P, Ostatníková D, Hodosy J. On the effects of testosterone on brain behavioral functions. Front Neurosci 2015; 9:12. doi: 10.3389/fnins.2015.00012.

29. Popova M. Researchers reveal sex differences in the brain's form and function. From: http://studopedia.org/11-34801.html Accessed: Jul 2016.

30. Zhu Z. Gender differences in mathematical problem solving patterns: A review of literature. Int Educ J 2007; 8:187-203.

31. Christov-Moore L, Simpson EA, Coudé G, Grigaityte K, Iacoboni M, Ferrari PF. Empathy: Gender effects in brain and behavior. Neurosci Biobehav Rev 2014; 46:604-27. doi: 10.1016/j.neubiorev.2014.09.001.

32. Science Daily. Intelligence in men and women is a gray and white matter. From: www.sciencedaily.com/releases/2005/ 01/050121100142.htm Accessed: Jul 2016.

33. Higher Purpose. How male and female brains work differently? From: www.dubheannk.com/tag/male-and-female-brain/ Accessed: Jul 2016

34. Davidson H, Cave KR, Sellner D. Differences in visual attention and task interference between males and females reflect differences in brain laterality. Neuropsychologia 2000; 38:508-19. doi: 10.1016/S0028-3932(99)00084-6. 